\title{
Influence of environmental parameters on benthic macroinvertebrate assemblages in the headwaters of Bagmati river, Kathmandu valley, Nepal
}

\author{
A. Rai ${ }^{*}$, D. N. Shah ${ }^{2}$, R. D. T. Shah ${ }^{3}$ and C. Milner ${ }^{4}$
}

The distribution of benthic macroinvertebrates (BMIs) is affected by various environmental factors. Understanding their response to these factors is a key to assessing freshwater quality. The aim of this research is to understand the influence of different environmental parameters on BMls assemblages in the headwaters of Bagmati river. The BMls were sampled following a multi-habitat sampling protocol and the - hydrological and physico-chemical parameters were measured using standard methods. The relationship between environmental parameters and macroinvertebrate assemblages was analyzed through Multivariate analysis - Redundancy Analysis and Variation Partitioning. Stream discharge, $\mathrm{pH}$ and Dissolved Oxygen were selected for multivariate analysis through backward elimination method. $\mathrm{pH}$ and Dissolved Oxygen were important contributing factors explaining the variation in BMls community. Physico-chemical parameters were found to be the most important group of variables explaining the variation in macroinvertebrate assemblages. Only about twenty-five per cent of the variation in the BMls community was explained by the model so the parameters studied here do not have a high degree of explanatory power.

Key words : Bagmati river, benthic macroinvertebrates, environmental parameters, headwaters, multivariate analysis

$\mathrm{T}$ The understanding on ecological status of streams and rivers help determine the ecosystem services provided by them (Grizzetti et al., 2016) so it is important to assess them. Water quality and ecological status is affected by a complex interaction of environmental factors. Understanding the relative effects of these environmental factors is a necessary step in determining the activities required for river management. The biological community is an ideal indicator to assess impacts as they respond to a wide variety of physical, chemical and biological factors. For such assessment, various biological components such as phytoplanktons
(Liu et al., 2017), zooplanktons (Ren et al., 2011), periphyton (Barbour et al., 1999), macrophytes (Haury et al., 2006), macroinvertebrates (Resh et al., 1995), fishes (Pont D. et al., 2006) etc. are used. Among these, stream benthic macroinvertebrates (BMIs) are especially well suited for assessing freshwater quality as their distributions have been linked to various environmental variables (Vinson and Hawkins, 1998). Notably, the BMIs have been used by the European Water Framework Directive 2000/60/EC for evaluation of the ecological quality of water (European Union Council, 2000). In Nepal as well, albeit in its early development the BMIs are being used in

\footnotetext{
NaayaAayam Multidisciplinary Institute, Jorpati, Kathmandu, Nepal *Email : raianu191@gmail. com

Central Department of Environmental Science, Tribhuvan University, Kirtipur, Nepal

Aquatic Ecology Centre, Kathmandu University, Dhulikhel, Nepal

Biosphere Association, UK
} 
the biological assessment of freshwater bodies (Shah et al., 2012; Shah and Shah, 2013).

The benthic macroinvertebrates are known to be the best biological indicators of freshwater quality as they exhibit different tolerance level to pollution, have high abundance, comparatively long-life and are available as cost effective means of sampling measure (Rosenberg and Resh, 1992). Benthic macroinvertebrates in nature are affected by various concurrently occurring environmental factors operating at multiple spatio-temporal scales. Some of these factors include physicochemical parameters (Collier et al., 1998), hydrological regimes (White et al., 2018), land use patterns (Helms et al., 2009), habitat type (Graeber et al., 2017), sediment characteristics (Jones et al., 2012), biotic interaction (Verschut et al., 2015) etc. This complex interaction makes it difficult to characterize the individual effects of each factor (Rempel et al., 2000). For instance, flow can induce the movement and deposition of fine sediment (Wood and Armitage, 1997) which can lead to turnover in macroinvertebrate assemblages through the accumulation of sediments (Buendia et al., 2013). Due to this complexity of interaction amongst environmental parameters, the study of the influence of a single parameter on BMIs assemblages may not be fully comprehensive. Their relative contributions have barely been quantified (Peeters et al., 2004) and despite its recognition there is dearth of knowledge on the relative contributions of these factors in influencing the benthic macroinvertebrate assemblages.

Headwaters have a very important role in the overall functioning of the river because they feed the whole watershed. The water and chemicals, headwaters hold influence all waters and reactions downstream (Alexander et al., 2007) and so, the studies of the effect of environmental parameters on macroinvertebrate assemblages particularly in the headwaters is essential. The headwaters of the Bagmati River lie in the Shivapuri Nagarjun National Park, representing a near-natural condition. Nevertheless, the streams are still influenced by human settlement and agricultural practices (Shrestha et al., 2014). The overall aim of the research is to understand the influence of environmental variables on benthic macroinvertebrate assemblages in the headwaters of Bagmati River to provide a baseline for further study downstream.

\section{Materials and methods}

\section{Study area}

The research was carried out in the headwaters of Bagmati River and its tributary - Nagmati River which lie in the Shivapuri Nagarjun National Park (SNNP) in Nepal. There were two sampling points in each River namely BA01 and BA02 in Bagmati and NA01 and NA02 in Nagmati (Fig. 1 and Table 1). The water temperature in the study sites varies from $4-24^{\circ} \mathrm{C}$ with the average temperature lying between $12-13^{\circ} \mathrm{C}$ (a data produced from a one-year average). The agricultural land use type has increased in the study area which has been attributed to increase in population among other reasons (Shrestha et al., 2014). The increase in population has resulted in forest deterioration causing reduction in water quantity and quality (Shrestha et al., 2014).

The study builds on a long-term biomonitoring project entitled - 'Understanding the impacts of climate change on headwater hydrology and aquatic biodiversity with long-term citizen science-based monitoring of the Bagmati River within the Shivapuri Nagarjun National Park' which has been in progress since 2015 (HimBioClic, 2017).

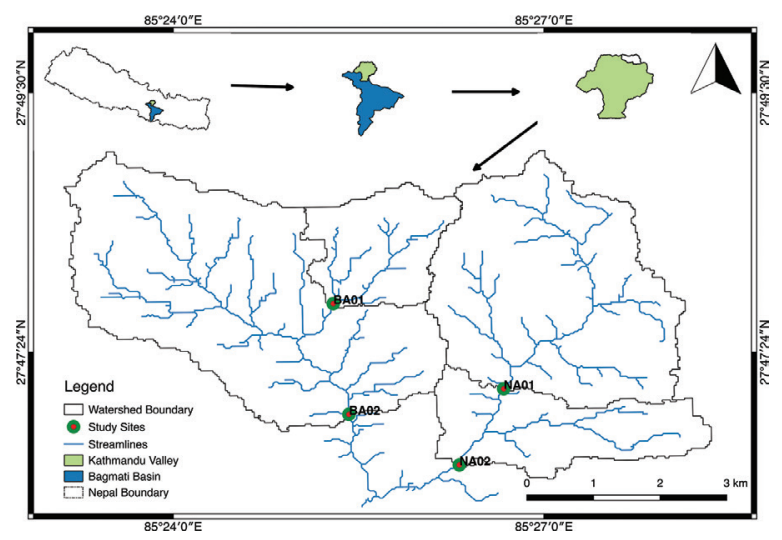

Fig. 1: Map showing the study area and the locations of the four sampling sites distributed in Nagmati (NA01, NA02) and Bagmati (BA01, BA02) River 
Table 1 : Description of sensory features and flow type at each study sites

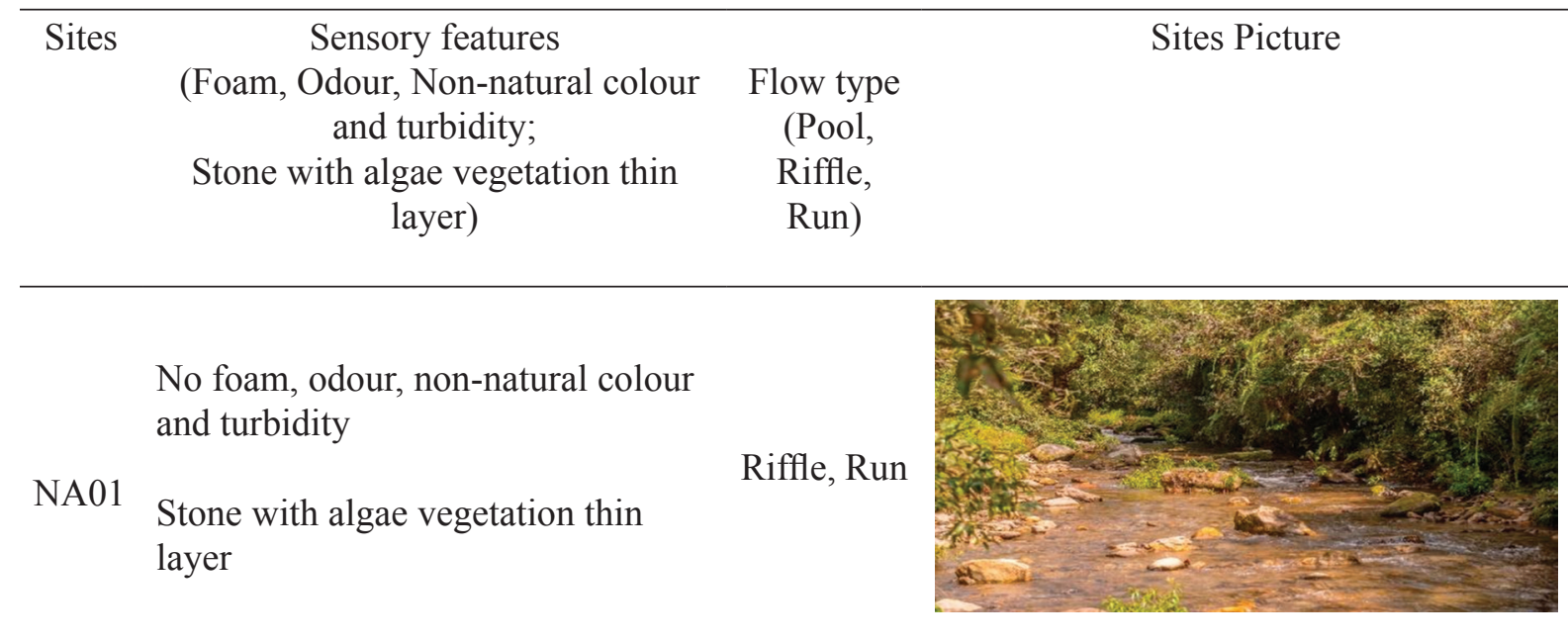

No foam, odour, non-natural colour
and turbidity
Stone with algae vegetation thin
layer

No foam, odour, non-natural colour and turbidity

BA02

Stone with algae vegetation thin layer

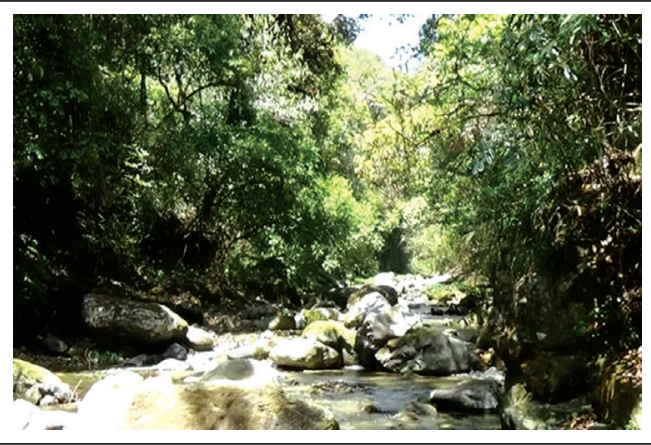

\section{Data collection}

The sampling of benthic macroinvertebrates was carried out and hydrological and physicochemical parameters were measured during the post-monsoon period of 2016 in October, November and December. Before sampling BMIs, the habitat coverage of river bed within $100 \mathrm{~m}$ of river stretch was estimated and the substrate consisting of at least $5 \%$ habitat coverage was sampled. This technique follows the multihabitat sampling approach (Moog, 2007) which is an enhancement over the traditional sampling procedures as it helps in sample collection across all the major habitat (Barbour et al., 2006). The BMIs were collected by using a kick net of $500 \mu \mathrm{m}$ mesh size from 20 micro-habitats and composited into a single sample. 
The discharge and the velocity of the River were measured using a Flow Tracker Handheld Acoustic Doppler Velocimeter (ADV). It has several Quality Control (QC) features designed to increase data integrity. Likewise, the River depth was measured by a staff gauge constructed in the study areas. The physico-chemical parameters $\mathrm{pH}$, water temperature, Dissolved Oxygen (DO), Total Dissolved Solids (TDS) and Electrical Conductivity (EC) were measured using a Handheld multi-parameter probe. The use of such multi-parameter portable meter is helpful in determining water quality parameters accurately on site which is a great advantage over lengthy laboratory procedures.

\section{Data analysis}

The benthic macroinvertebrates were processed in the laboratory - sorted and identified at family level. Then they were counted and preserved in $90 \%$ ethanol for future reference. References used in identification include Dudgeon (1999), Wagner (2004), Bouchard (2004), Nesemann et al., (2007) and Nesmann et. al. (2011).

The relationship between environmental variables and BMIs assemblage were evaluated through Redundancy Analysis using rda function in vegan package (Oksanen et al., 2019) in R Studio Version 1. 2. 1335. The appropriate ordination technique - whether Redundancy Analysis (RDA) or Canonical Correspondence Analysis (CCA) was selected by performing Detrended Correspondence Analysis (DCA) (ter Braak et al., 2002). The gradient length was found to be less than three standard deviations; hence RDA was performed (ter Braak et al., 2002). Prior to RDA analysis, the BMIs abundance data were square root transformed (Hellinger transformation in vegan package in $\mathrm{R}$ ) and the environmental variables were log-transformed to put them all at the same scale. Variance inflation factors (VIF) were measured and variables with VIF $>20$ were removed from the analysis. Then, backward elimination method was performed with 500 permutation with ordistep function for removing variables until only significant ones remained. Finally, RDA was performed amongst Hellinger transformed BMIs abundance data with the remaining log- transformed explanatory variables.

Besides, Variation Partitioning method was performed for quantifying the contribution of different environmental variables in structuring BMIs assemblages using varpart function in vegan package.

\section{Results and discussion}

Eleven orders of macroinvertebrates consisting of fifty-one families were found in the study area (Fig. 2). The order Diptera consisted of ten macroinvertebrate families dominating the BMI assemblage and the least families of macroinvertebrates were from orders Arhynchobdellida, Lepidoptera and Megaloptera where only one family of macroinvertebrate was found. In all sites, the highest number of macroinvertebrate order was found in December except for site NA01 where the highest number of macroinvertebrate order was found in November.

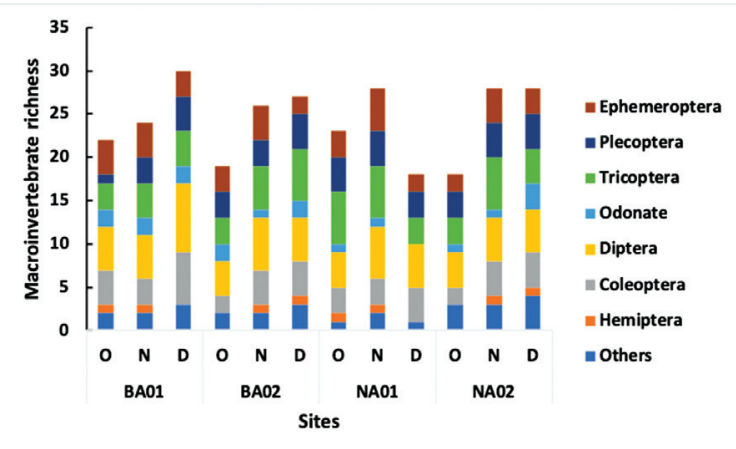

Fig. 2: Macroinvertebrate richness in the study sites. $\mathrm{O}, \mathrm{N}$ and $\mathrm{D}$ represent the months of October, November and December 2016 respectively

Likewise, the highest proportion of macroinvertebrates was found from EPT taxa (Fig. 3) which indicates good water quality in all sites. In a previous study, headwaters were found in good ecological status (Shah and Shah, 2013) which represents that despite the rapid and haphazard development of Kathmandu valley, the headwaters seem to have retained its ecological integrity. Except for site BA02 in the month of December, all sites had the highest relative abundance of EPT taxa. 


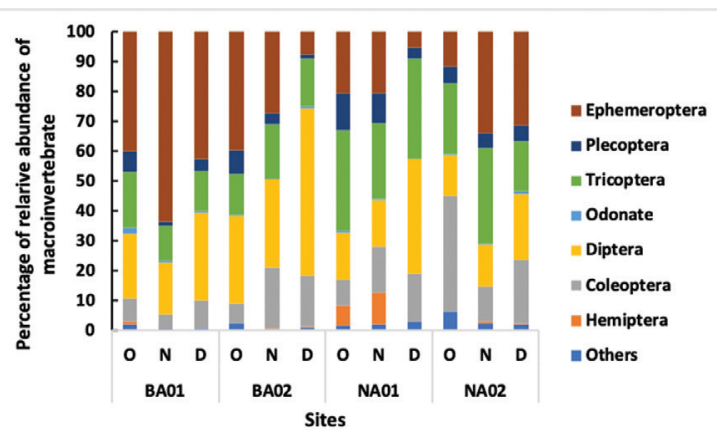

Fig. 3: Percentage of relative abundance of macroinvertebrate in the study sites. $\mathrm{O}, \mathrm{N}$ and $D$ represent the months of October, November and December 2016, respectively

The constrained axes in the multivariate analysis explained about thirty percent of the total variation in the samples and among the proportion of the constrained axes, the two RDA axes explained about seventy-five per cent of the total variation. For each of these explanatory variables a correlation was obtained with the RDA axis (Table 2). $\mathrm{pH}$ clearly has a high negative correlation with the second ordination axis and to a lesser extent discharge also displays a negative correlation with the first ordination axis.

Table 2 : Biplot score for the constraining variables in three RDA axes

\begin{tabular}{|l|l|l|l|}
\hline Parameter & RDA1 & RDA2 & RDA3 \\
\hline Discharge & -0.14 & 0.38 & 0.92 \\
\hline $\mathrm{pH}$ & 0.27 & -0.94 & 0.23 \\
\hline $\mathrm{DO}$ & 0.80 & 0.52 & 0.30 \\
\hline
\end{tabular}

The multivariate analysis showed that different environmental variables explain variation in BMIs assemblages (Fig. 4). For instance : BMIs families like Ephemeridae and Baetidae (Ephemeroptera) showed positive correlation with Dissolved Oxygen meaning these species tend to have larger abundance at higher DO. Likewise, Gyrinidae, Empididae and Capniidae have shown positive correlation with $\mathrm{pH}$ also meaning they have higher probability of occurrence at higher $\mathrm{pH}$.

From the analysis, it was found that $\mathrm{pH}$ and $\mathrm{DO}$ were the two most important variables explaining the variation in macroinvertebrate assemblages $\left(r^{2}=0.89, p\right.$-value $=0.001$ and $r^{2}=0.69$ and p-value $=0.005$ respectively with respect to the two RDA axes). These findings agree with other documentation where higher DO has been seen to be positively associated with EPT taxa as these taxa mostly contain sensitive organisms (Merritt and Cummins, 1996). However, with regard to $\mathrm{pH}$ even within same BMIs taxonomic groups, variable responses have been seen both spatially and temporally (Petrin et al., 2007), so a study of relationship of BMIs along a $\mathrm{pH}$ - gradient is needed to robustly justify the results presented here.

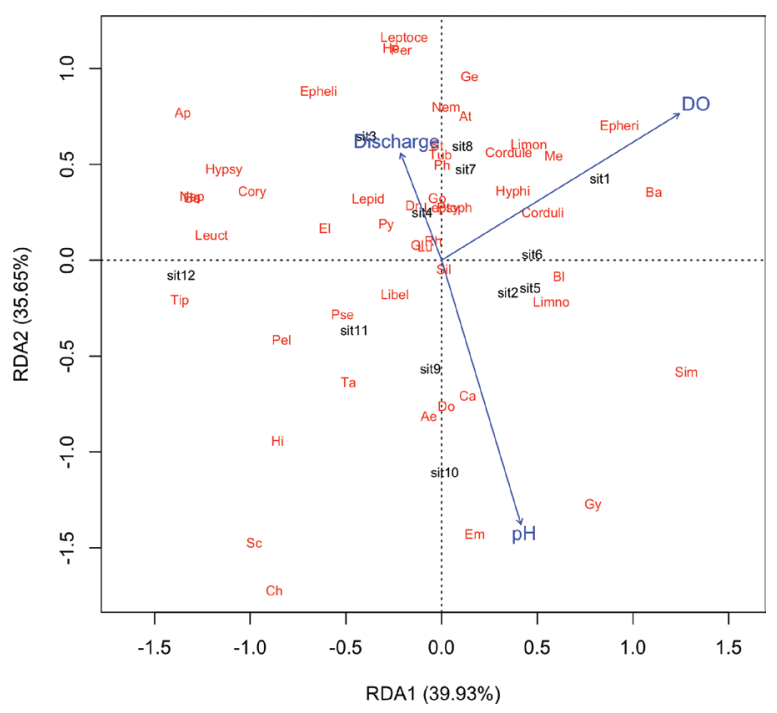

Fig. 4: Redundancy analysis triplot of the Hellinger transformed macroinvertebrates abundance data constrained by environmental parameters with scaling 1. Sit1-Sit4, Sit5Sit8 and Sit9-Sit12 represent the sites BA01, BA02, NA01, NA02 in October, November and December, respectively. ${ }^{1}$

About twenty-five per cent of the total variation in the macroinvertebrate assemblages was explained by the variables included in the

1 The macroinvertebrate acronym represent $-\mathrm{Ae}=$ Aeshnidae, $\mathrm{Ap}=$ Aphelocheiridae, $\mathrm{At}=$ Athericidae, $\mathrm{Ba}=$ Baetidae, $\mathrm{Bl}$ $=$ Blephariceridae, $\mathrm{Ca}=$ Capniidae, $\mathrm{Ce}=$ Ceratopogonidae, $\mathrm{Ch}=$ Chironomidae, Cordule $=$ Cordulegastridae, Corduli $=$ Cordulidae, Cory $=$ Corydalidae, Do $=$ Dolichopodidae, Dr $=$ Dryopidae, $\mathrm{El}=$ Elmidae, $\mathrm{Em}=$ Empididae, Epheli $=$ Ephemerellidae, Epheri $=$ Ephemeridae, $\mathrm{Ge}=$ Gerridae, $\mathrm{Gl}=$ Glossosomatidae, Go $=$ Gomphidae, Gy $=$ Gyrinidae, $\mathrm{Ha}=$ Haliplidae, $\mathrm{He}=$ Heptageniidae, $\mathrm{Hi}=$ Hirudinidae, Hyphi $=$ Hydrophilidae, Hypsy = Hydropsychidae, Lepid $=$ Lepidostomatidae, Leptoce $=$ Leptoceridae, Leptoph $=$ Leptophlebiidae, Leuct $=$ Leuctridae, Libel = Libellulidae, Limno $=$ Limnocentropodidae, Limon $=$ Limonidae, $\mathrm{Lu}=$ Lumbricidae, $\mathrm{Me}=$ Megascolecidae, Nem = Nemouridae, Nep $=$ Nepidae, Pel $=$ Peltoperlidae, Per $=$ Perlidae, $\mathrm{Ph}=$ Philopotamidae, Pse $=$ Psephanidae, Psy $=$ Psychomyiidae, Py $=$ Pyralidae, $\mathrm{Rh}=$ Rhyacophilidae, $\mathrm{Sc}=$ Scirtidae, $\mathrm{Sil}=$ Silphidae, $\mathrm{Sim}=$ Simulidae, $\mathrm{St}=$ Stenopsychidae, $\mathrm{Ta}=$ Tabanidae, $\mathrm{Tip}=$ Tipulidae, $\mathrm{Tu}=$ Tubificidae 
analysis (Fig. 5). The highest variation in BMIs assemblage was explained by physico-chemical parameter supporting the study by Dalu et al., (2017). However, the study had used sediment characteristics as one of the groups of explanatory variables, also the variables chosen under water chemistry and physical variables were slightly different than the present study. Nevertheless, the strong effect of water chemistry is remarked in both the studies. The results of Variation Partitioning depend on the type of variables selected for the analysis. The low partial effects between the variables reflected that the parameters had lower joint effect in explaining the variation in BMIs assemblage, acting almost independently from one another in explaining the variation in BMIs assemblages.

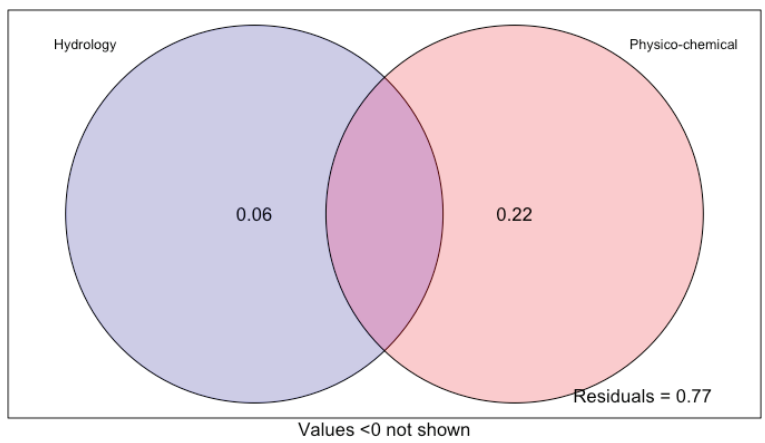

Fig. 5: Variation partitioning showing the relationshipofdifferentgroups ofenvironmental variables and macroinvertebrate abundance data

The high residual value showed that the parameters studied here had little influence on macroinvertebrate assemblages. The other parameters which could explain the variation in macroinvertebrate assemblages could be sediment type (Peeters et al., 2004), habitat characteristics (Graeber et al., 2017), biological factors (Verschut et al., 2015) etc. Besides, the study only considered headwaters and used local environmental conditions in explaining the variation in the BMIs assemblages. Moreover, the scale of analysis could also have yielded such high residual value. As Mykrä et al. (2007) had shown that the stream macroinvertebrate assemblages are not only constrained by the local environmental factors but also depend on the biogeographical and neighborhood dispersal processes. Furthermore, these dispersal processes are governed by dendritic landscape structure and the environmental conditions are itself linked to the network position (Altermatt et al., 2013). Moreover, on a larger scale, such as a regional scale different groups of variables could explain the variation in macroinvertebrate assemblages. In a study by Shah et al. (2015) partition of the total variation in stream insects were explained by variables like climate, spatial and topography. The unexplained variations were also seen in this study which could be explained by other local factors, biogeographical factors or consideration of dendritic landscape structure. Hence, to ascertain the effect of different environmental variables on macroinvertebrates, analysis of multiple parameter considering position in dendritic landscape structure along with the scale of analysis is a necessity.

\section{Conclusion}

This research shows that the macroinvertebrate assemblages are constrained by a variety of environmental factors. The relative significance of different groups of environmental variables in structuring the macroinvertebrate assemblages were also found to be variable. Since the physicochemical explanatory groups were assessed to be the most important group of variables in structuring BMIs assemblages, the alteration in physico-chemical parameters of the streams should be carefully considered.

However, the environmental variables studied had little influence on the macroinvertebrate family level communities. Thus, a more rigorous study which takes into consideration various other factors at multiple scales are required to better understand the relationship between the macroinvertebrate assemblages and its constraining variables in the headwaters of Bagmati River. The results obtained can be used as baseline information for further research.

\section{Acknowledgements}

I would like to thank Himalayan Biodiversity and Climate Change Center and Biosphere Association for funding this research and for providing me with temperature data (used as average for the study sites). I would also like to thank my colleagues Ms. Anusha Pandey, Mr. Nischal Devkota and Ms. Bhumika Thapa and many other research volunteers for helping me in conducting the field survey and laboratory 
analysis. Besides, I would like to thank to Dr. Anish Ghimire for the consultation on data analysis. Furthermore, I would also like to thank Mr. Jeff Davids for teaching me the procedures of using Flow meter and for preliminary consultation on the use of GIS datasets. I would like to express my sincere gratitude to the lecturers and management at NAMI College for their academic support and provision of laboratory equipment. I would also like to thank the Department of National Parks and Wildlife Conservation and Shivapuri Nagarjun National Park for permitting to conduct the field work.

\section{References}

Alexander, R. B., Boyer, E. W., Smith, R. A., Schwarz, G. E. and Moore, R. B. 2007. The Role of Headwater Streams in Downstream Water Quality. Journal of the American Water Resources Association 43 (1) : 4159.

Altermatt, F., Seymour, M. and Martinez, N. 2013. River network properties shape $\alpha$-diversity and community similarity patterns of aquatic insect communities across major drainage basins J. Sadler, ed. Journal of Biogeography 40 (12) : 2249-2260.

Barbour, M. T., Gerritsen, J., Snyder, B. D. and Stribling, J. B. 1999. Rapid bioassessment protocols for use in streams and wadeable rivers : periphyton, benthic macroinvertebrates and fish. US Environmental Protection Agency, Office of Water Washington, DC.

Barbour, M. T., Stribling, J. B. and Verdonschot, P. F. M. 2006. The multihabitat approach of USEPA's rapid bioassessment protocols : benthic macroinvertebrates. Limnetica 25 : 839-850.

Bouchard, W. 2004. Guide to Aquatic Invertebrates of the Upper Midwest. University of Minnesota

Buendia, C., Gibbins, C. N., Vericat, D. and Batalla, R. J. 2013. Effects of flow and fine sediment dynamics on the turnover of stream invertebrate assemblages : Effects of Fine Sediment Dynamics on
Beta-Diversity of Stream Invertebrates. Ecohydrology 7 : 1105-1123.

Collier, K. J., Ilcock, R. J. and Meredith, A. S. 1998. Influence of substrate type and physico chemical conditions on macroinvertebrate faunas and biotic indices of some lowland Waikato, New Zealand, streams. New Zealand. Journal of Marine and Freshwater Research 32 (1) : 1-19.

Dalu, T., Wasserman, R. J., Tonkin, J. D., Mwedzi, T. Magoro, M. L. and Weyl, O. L. F. 2017. Water or sediment? Partitioning the role of water column and sediment chemistry as drivers of macroinvertebrate communities in an austral South African stream. Science of The Total Environment 607-608 : 317325.

Dudgeon, D. 1999. Tropical Asian Streams : Zoobenthos, Ecology and Conservation. Hong Kong University Press.

European Union Council, 2000 Directive 2000/60/EC of the European Parliament and of the Council of 23 October 2000 establishing a framework for Community action in the field of water policy. Journal of the European Communities 43 : 39-58.

Graeber, D., Jensen, T. M., Rasmussen, J. J., Riis, T., Wiberg-Larsen, P. and BaattrupPedersen, A. 2017. Multiple stress response of lowland stream benthic macroinvertebrates depends on habitat type. Science of The Total Environment 599-600 : 1517-1523.

Grizzetti, B., Lanzanova, D.,Liquete, C., Reynaud, A. and Cardoso, A. C. 2016. Assessing water ecosystem services for water resource management. Environmental Science and Policy 61 : 194-203.

Haury, J., Peltre, M. C., Trémolières, M., Barbe, J., Thiébaut, G., Bernez, I., Daniel, H., Chatenet, P., Haan-Archipof, G. and Muller, S. 2006. A new method to assess water trophy and organic pollution-the Macrophyte Biological Index for Rivers (IBMR) : its application to different types of river and pollution. In Macrophytes 
in aquatic ecosystems : From biology to management. Springer, 153-158.

Helms, B. S., Schoonover, J. E. and Feminella, J. W. 2009. Seasonal variability of landuse impacts on macroinvertebrate assemblages in streams of western Georgia, USA. Journal of the North American Benthological Society 28 (4) : 991-1006.

HimBio-Clic, 2017 Ongoing Projects. Himalayan Biodiversity and Climate Change Center, 2017. (HimBio-Clic) [online]. http ://www. biodiversity. org. np/index. php?page $=$ ongoing-projects $\quad[15$ June, 2019].

Jones, J. I., Murphy, J. F., Collins, A. L., Sear, D. A., Naden, P. S., Armitage and P. D. 2012. The Impact of Fine Sediment on Macro-Invertebrates. River Research and Applications 28 (8) : 1055-1071.

Liu, Y.F., Sun, L. C., Jiang, Y.L. 2017. Bibliometric review of research on phytoplankton in water quality assessment. Acta Ecologica Sinica 37 (3) : 165-172.

Merritt, R. W., Cummins and K. W. 1996. An introduction to the aquatic insects of North America. Kendall Hunt.

Moog, O. 2007. "Manual on pro-rata multihabitat-sampling of benthic invertebrates from wadeable rivers in the HKH region" paper presented at Deliverable 8, Part 1 for ASSESS-HKH, European Commission.

Mykrä, H., Heino, J. and Muotka, T. 2007. Scale-related patterns in the spatial and environmental components of stream macroinvertebrate assemblage variation. Global Ecology and Biogeography 16 (2) : 149-159.

Nesemann, H., Sharma, S., Sharma, G., Khanal, S.N., Pradhan, B., Shah, D.N. and Tachamo, R.D. 2007. Aquatic invertebrates of the Ganga River System. First edition. Kathmandu, Nepal.

Nesemann, H., Shah, R. D. T. and Shah, D. N. 2011. Key to the larval stages of common
Odonata of Hindu Kush Himalaya, with short notes on habitats and ecology. Journal of threatened Taxa 3 (9) : 2045-2060.

Oksanen, J., Blanchet, F. G., Friendly, M., Kindt, R., Legendre, P., McGlinn, D., Minchin, P. R., O'Hara, R. B., Simpson, G. L., Solymos, P., Stevens, M. H. H., Szoecs, E. and Wagner, H. 2019. vegan : Community Ecology Package (Version 2. 5-5). [online] https ://CRAN. R-project. org/package=vegan[15 June, 2019].

Peeters, E. T., Gylstra, R. and Vos, J. H. 2004. Benthic macroinvertebrate community structure in relation to food and environmental variables. Hydrobiologia 519 (1) : 103-115.

Petrin, Z., Laudon and H., Malmqvist, B. 2007. Does freshwater macroinvertebrate diversity along a $\mathrm{pH}$ gradient reflect adaptation to low $\mathrm{pH}$ ?. Freshwater Biology 52 (11); 2172-2183.

Pont D., Hugueny B., Beier U., Goffaux D., Melcher A., Noble R., Rogers C., Roset N. and Schmutz S. 2006. Assessing river biotic condition at a continental scale : a European approach using functional metrics and fish assemblages. Journal of Applied Ecology 43 (1) : 70-80.

Rempel, L. L., Richardson, J. S., Healey and M. C. 2000. Macroinvertebrate community structure along gradients of hydraulic and sedimentary conditions in a large gravelbed river. Freshwater Biology 45 (1) : $57-73$

Ren, L., Zhang, Z., Zeng, X., Ma, Y., Zeng, Y., Zhou and C. 2011. Community Structure of Zooplankton and Water Quality Assessment of Jialing River in Nan Chong. Procedia Environmental Sciences 10 : 1321-1326.

Resh, V. H., Norris, R. H., Barbour and M. T. 1995. Design and implementation of rapid assessment approaches for water resource monitoring using benthic macroinvertebrates. Austral Ecology 20 (1) $108-121$. 
Rosenberg, D. M. and Resh, V. H. 1992. Freshwater Biomonitoring and Benthic Macroinvertebrates. Springer.

Shah, D. N., Shah, R. D. T. and Pradhan, B.K. 2012. Diversity and Community Assemblage of Littoral Zone Benthic Macroinvertebrates in Jagadishpur Reservoir. Nepal Journal of Science and Technology 12 : 211-219.

Shah, R. D. T., Shah and D. N. 2013. Evaluation of benthic macroinvertebrate assemblage for disturbance zonation in urban rivers using multivariate analysis : Implications for river management. Journal of earth system science 122 (4) : 1125-1139.

Shrestha, S., Joshi, L. and Dangol, M. 2014. Assessment of Land Use Change in Shivapuri Nagarjun National Park : The Case of Sundarijal VDC, Kathmandu. Ecoprint : An International Journal of Ecology 20 : 53-59.

terBraak, C. J. F., Smilauer, P., Smilauer, P., Smilauer, P. and Smilauer, P. 2002. Canoco Reference Manual and CanoDraw for Windows User's Guide : Software for Canonical Community Ordination (version 4. 5). Microcomputer Power, Ithaca, USA.
Verschut, T. A., Meineri, E. and Basset, A. 2015. Biotic interactions affect the colonization behavior of aquatic detritivorous macroinvertebrates in a heterogeneous environment. Estuarine, Coastal and Shelf Science 157 : 120-128.

Vinson, M. R., Hawkins and C. P. 1998. Biodiversity of stream insects : variation at local, basin, and regional scales. Annual Review of Entomology 43 : 271-293.

Wagner, R. 2004. Freshwater invertebrates of the Malaysian region. Academy of Sciences Malaysia 634-637.

White, J. C., House, A., Punchard, N., Hannah, D. M., Wilding, N. A. and Wood, P. J. 2018. Macroinvertebrate community responses to hydrological controls and groundwater abstraction effects across intermittent and perennial headwater streams. Science of the Total Environment 610 : 1514-1526.

Wood, P. J. and Armitage, P. D. 1997. Biological Effects of Fine Sediment in the Lotic Environment. Environmental Management $21(2): 203-217$. 